\section{Cureus}

Received 07/14/2014

Review began 07/15/2014

Review ended 07/20/2014

Published 07/21/2014

\section{(C) Copyright 2014}

Jusue Torres et al. This is an open access article distributed under the terms of the Creative Commons Attribution License CC-BY 3.0., which permits unrestricted use, distribution, and reproduction in any medium, provided the original author and source are credited.

\title{
Complications of Lumboperitoneal Shunts for Idiopathic Intracranial Hypertension
}

Ignacio J. Jusue Torres ${ }^{1}$, Jamie B. Hoffberger ${ }^{2}$, Daniele Rigamonti ${ }^{2}$

1. Department of Neurosurgery, Loyola University Chicago, Stritch School of Medicine, Maywood, Illinois, Chicago, USA 2. Department of Neurosurgery, The Johns Hopkins University School of Medicine

$\square$ Corresponding author: Ignacio J. Jusue Torres, ignaciojusue@gmail.com

Disclosures can be found in Additional Information at the end of the article

\section{Abstract}

For the past half century, the mainstay of cerebrospinal fluid (CSF) shunting for idiopathic intracranial hypertension (IIH) has been lumboperitoneal (LP) shunt surgery. LP shunts have been associated with higher failure rates compared to ventriculoperitoneal shunts. However, there is no uniformity in the reporting of complication and surgical revision rates.

The goals of this study were to understand better the complications and surgical revision rates associated with LP shunt insertion in IIH patients with the objective of providing better information about the different therapeutical option outcomes when counseling for a better informed consent.

Twenty-six patients with IHH undergoing lumboperitoneal shunt surgery for the first time by the senior author at an academy tertiary-care institution were retrospectively reviewed. Presence of complications and surgical revisions were the two main outcome variables. Logistic regression analysis was used first to assess if there was a correlation between preoperative patient characteristics and complications and second to evaluate if there was any association between preoperative patient characteristics or postsurgical complications and surgical revision.

Primary shunts were inserted into 26 patients and 58\% required revision surgery. Median time to surgical revision was four (3-22) months. Multivariate logistic analysis showed no statistical significant association between preoperative patient characteristics and postoperative complications as well as no relationship between either preoperative characteristics or complications and surgical revisions.

Our data suggests that our revisions were mostly performed to reduce the rate of post-LP shunt tonsillar herniation. The introduction of newer hardware is expected to positively impact the symptoms and signs of overdrainage post-LP shunt placement and the need for revision.

Categories: Neurology, General Surgery, Neurosurgery

Keywords: complication, idiopathic intracranial hypertension, follow-up, lumboperitoneal shunt, pseudotumor cerebri, reoperation, surgical revision

\section{Introduction}

For the past half century, the mainstay of cerebrospinal fluid (CSF) shunting for idiopathic intracranial hypertension (IIH) also known as pseudotumor cerebri syndrome (PTC) has been lumboperitoneal (LP) shunt surgery [1-2]. In some institutions, the LP shunt comprises up to 
$40 \%$ of all CSF shunting procedures [3-4]. One of the reasons that LP shunt is used when treating patients with $\mathrm{IIH}$ is because of the difficulty placing the proximal catheter in ventricles that are usually quite small [5]. Furthermore, LP shunt eliminates the small risk of intracranial hemorrhage associated with the introduction of a catheter through the brain parenchyma. Nowadays, given the better understanding of the pathogenetic mechanism of IIH, the primary therapeutic intervention aims at curing the condition by reducing patients' weight (diet, bariatric surgery, etc.) and/or eliminating dural sinus stenosis by insertion of a cerebral venous sinus stent [6-7]. LP shunt and optic nerve fenestration (ONF), being palliative treatments, should only be offered when the first two have failed or in an emergency situation. On the other hand, LP shunt has been associated with higher failure rates compared to ventriculoperitoneal shunts [1-2, 8-13]. However, there is no uniformity in the reporting of complication and surgical revision rates [2, 12-15]. Differences in the size of previous cohorts' studies as well as the tendency to under-report poor outcomes may explain this regrettable situation $[1,12,16$ 34]. We conducted the present study with the intention to understand better the complications and surgical revision rates associated with LP shunt insertion in IIH patients to help when informing patients about the outcomes of the different treatments with the objective of providing better information about the different therapeutical option outcomes when counseling and a better informed consent.

\section{Materials And Methods}

Institutional Review Board (IRB) approval (\#44584) was obtained prior to the start of this study. Informed patient consent was obtained from all patients involved in this study.

All adult patients (age > 18) that received primary placement of LP shunt with horizontalvertical $(\mathrm{H}-\mathrm{V})$ lumbar valve systems as treatment of IIH by the senior author were included. Exclusion criteria were comprised of conditions other than IIH, non-primary placed LP shunts, and pediatric patients.

From 1994 to 2013, there were a total of 41 adult patients who underwent lumboperitoneal shunt surgery for the first time by the senior author at a single academic tertiary-care institution. Patients $(n=15)$ with hydrocephalus, preoperative CSF leak, multiple sclerosis, and syringomyelia were excluded. In total, 26 patients met the inclusion criteria.

The clinical records of the included patients were retrospectively reviewed. The information collected from clinical notes included: demographics, body mass index (BMI), presenting symptoms (headache, vision problems, nausea, vomit, photophobia, phonophobia), optic neuropathy, papilledema, etiology (dural venous sinus stenosis, infectious, traumatic, hemorrhagic, unknown), opening pressure in mmHg, follow-up time in months, and valve characteristics.

Presence of complications and surgical revisions were the two main outcomes variables. Data was collected on the number of surgical revisions per patient, time to revision in months, conversion to other type of shunt, reprogramming, change in the type of valve, optic nerve fenestration, subtemporal decompression craniectomy, and suboccipital decompression. Missing data was documented.

Summary data is presented as frequencies, percentage for categorical variables, and median and interquartile range (IQR) for continuous variables. Logistic regression analysis was used to assess if there was a correlation between preoperative patient characteristics and complications. This same analysis was used to evaluate if there was any association between preoperative patient characteristics or postsurgical complications and surgical revision. Statistically significant differences were considered when $\mathrm{p}<0.05$. 


\section{Cureus}

Overall time required for surgical revision was plotted using the Kaplan-Meier method ( $\mathrm{R}$ statistic software, version 3.0.1) [35].

\section{Results}

Twenty-six patients underwent lumboperitoneal shunting to treat IIH over the 20-year study period. Patient characteristics are shown in Table 1. 


\section{Cureus}

\begin{tabular}{|c|c|}
\hline & IIH n=26 (\%) \\
\hline Age (years) & $34(30-43)$ \\
\hline Female: Male & 21/5 (4.2:1) \\
\hline White & $18(69 \%)$ \\
\hline African-American & $5(19 \%)$ \\
\hline BMI & $36(30-41)$ \\
\hline Obesity & $17(65 \%)$ \\
\hline Morbid Obesity & $8(31 \%)$ \\
\hline Headache & $22(85 \%)$ \\
\hline Vision problems & $17(65 \%)$ \\
\hline Nausea & $6(23 \%)$ \\
\hline Vomit & $4(15 \%)$ \\
\hline Photophobia & $2(8 \%)$ \\
\hline Phonophobia & $2(8 \%)$ \\
\hline Cognitive impairment & $2(8 \%)$ \\
\hline Optic neuropathy & $16(62 \%)$ \\
\hline Papilledema & $14(54 \%)$ \\
\hline \multicolumn{2}{|l|}{ Etiology } \\
\hline Unknown & $19(73 \%)$ \\
\hline Sinus stenosis & $4(15 \%)$ \\
\hline Traumatic & $2(8 \%)$ \\
\hline Infectious & $1(4 \%)$ \\
\hline Hemorrhagic & $0(0 \%)$ \\
\hline Opening pressure $\left(\mathrm{mm} \mathrm{H}_{2} \mathrm{O}\right)$ & $350(330-440)$ \\
\hline Follow up time (years) & $4(1-8)$ \\
\hline
\end{tabular}

\section{TABLE 1: Patient characteristics.}

Data is presented as frequencies (percentage) for categorical variables and median (interquartile range) for continuous variables.

Median follow-up (IQR) was four (1-8) years. Median age (IQR) was 34 (30-43) years old. Female/male ratio was 4.2:1 and median body mass index (IQR) 36 (30-41) with $65 \%$ of obese 


\section{Cureus}

patients and $31 \%$ of morbid-obese patients. The most common presenting symptoms were headache (85\%), vision problems (65\%), nausea (24\%), vomiting (15\%), photophobia (8\%), phonophobia (8\%), and cognitive impairment (8\%). Patients with IIH showed papilledema in $54 \%$ of cases and optic neuropathy in 62\%. Median opening pressure (IQR) was 350 (330-440) $\mathrm{mm} \mathrm{H}_{2} \mathrm{O}$.

In our series, we found that 18 shunts patients (69\%) developed at least one complication. Complication characteristic details are shown in Figures 1,2 and Table 2.

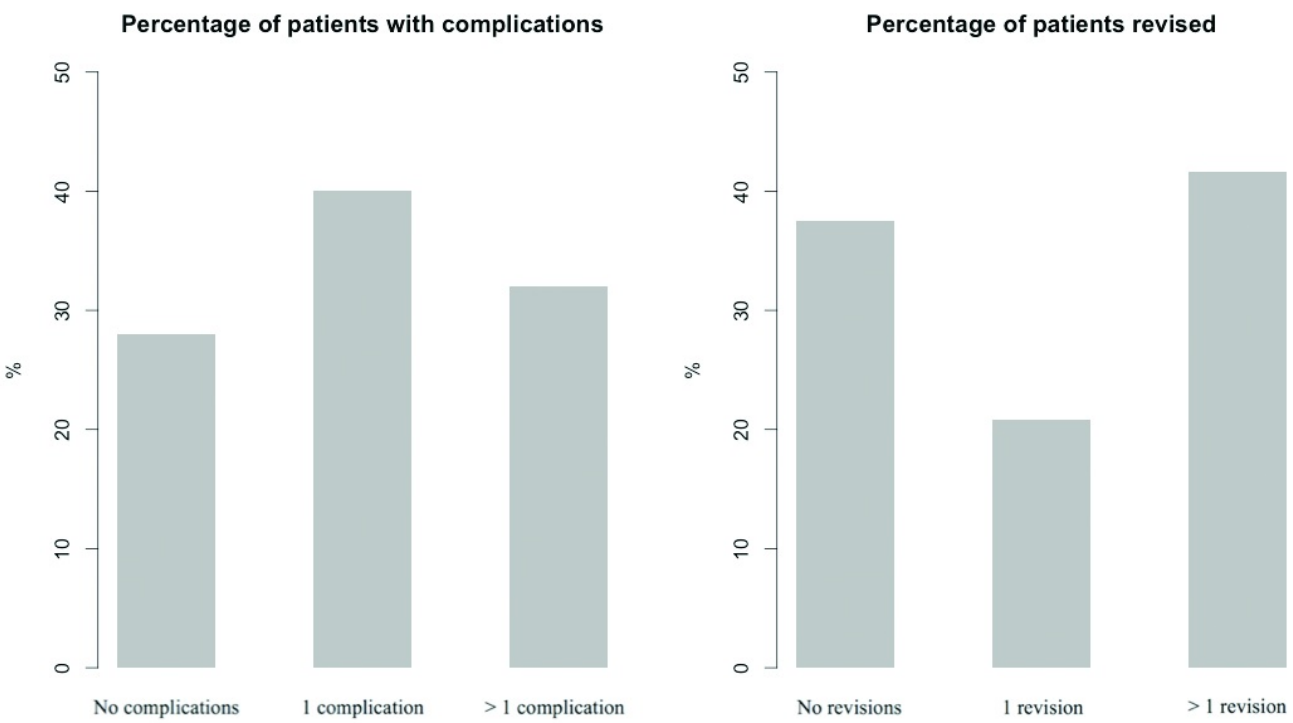

FIGURE 1: Barplots showing: A) Percentage of LP shunt patients with no complications, one complication, or more than one complication.

B) Percentage of LP shunt patients with no surgical revisions, one surgical revision, or more than one surgical revision.
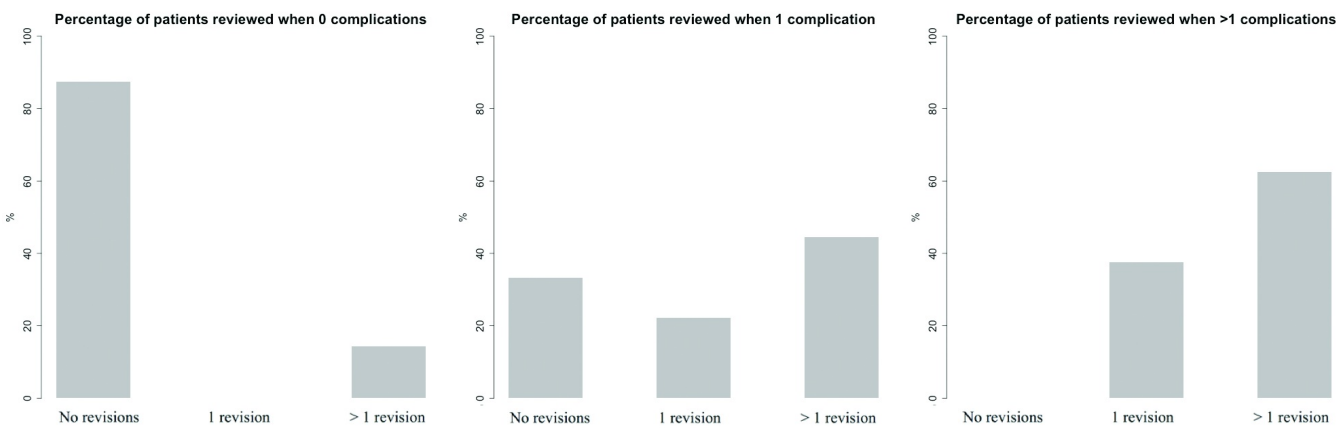

FIGURE 2: Barplots showing: A) Percentage of LP shunt patients with no complications that get no surgical revisions, one surgical revision, or more than one surgical revision.

B) Percentage of LP shunt patients with one complication that get no surgical revisions, one 


\section{Cureus}

surgical revision, or more than one surgical revision. C) Percentage of LP shunt patients with more than one complication that get no surgical revisions, one surgical revision, or more than one surgical revision.

\begin{tabular}{ll}
\hline Overdrainage & IIH $\mathbf{n = 2 6}(\%)$ \\
Obstruction & $9(35 \%)$ \\
CSF leak & $5(19 \%)$ \\
Abdominal pain & $4(15 \%)$ \\
Infection & $4(15 \%)$ \\
Wound dehiscence & $2(8 \%)$ \\
Tinnitus & $2(8 \%)$ \\
Back pain & $1(4 \%)$ \\
Radiculopathy & $1(4 \%)$ \\
Hearing loss & $1(4 \%)$ \\
Pseudomeningocele & $0(0 \%)$ \\
TOTAL \# of PATIENTS WITH COMPLICATIONS & $0(0 \%)$ \\
\hline
\end{tabular}

\section{TABLE 2: Post-LP shunt complications}

Among the patients that received LP shunt, 58\% required revision surgery $(n=15)$. Further details are shown in Figures 1, 2 as well as Table 3. Among subjects requiring a shunt revision, $33 \%$ ( 5 out of 15 ) had one revision while $66 \%$ (10 out of 15 ) required multiple revisions. Notably, 20\% (3 out 15) subjects required five or more revisions (range 5-10 revisions). Therefore, primary shunts were inserted into 26 patients and 53 revision surgeries were required. Median time to surgical revision was four (3-22) months (Figure 3). 


\section{Cureus}

\begin{tabular}{|l|l|}
\hline Number of patients surgically revised & IlH $\mathbf{n = 2 6 ( \% )}$ \\
\hline Patients that required multiple revisions & $16(58 \%)$ \\
\hline Time to revision (months) & $10(39 \%)$ \\
Conversion to other type of shunt & $4(3-22)$ \\
Change of type of valve & $11(42 \%)$ \\
Reprogramming & $2(8 \%)$ \\
Subtemporal decompression craniectomy & $1(4 \%)$ \\
Suboccipital decompression & $1(4 \%)$ \\
\hline
\end{tabular}

\section{TABLE 3: Surgical revisions post-LP shunt.}

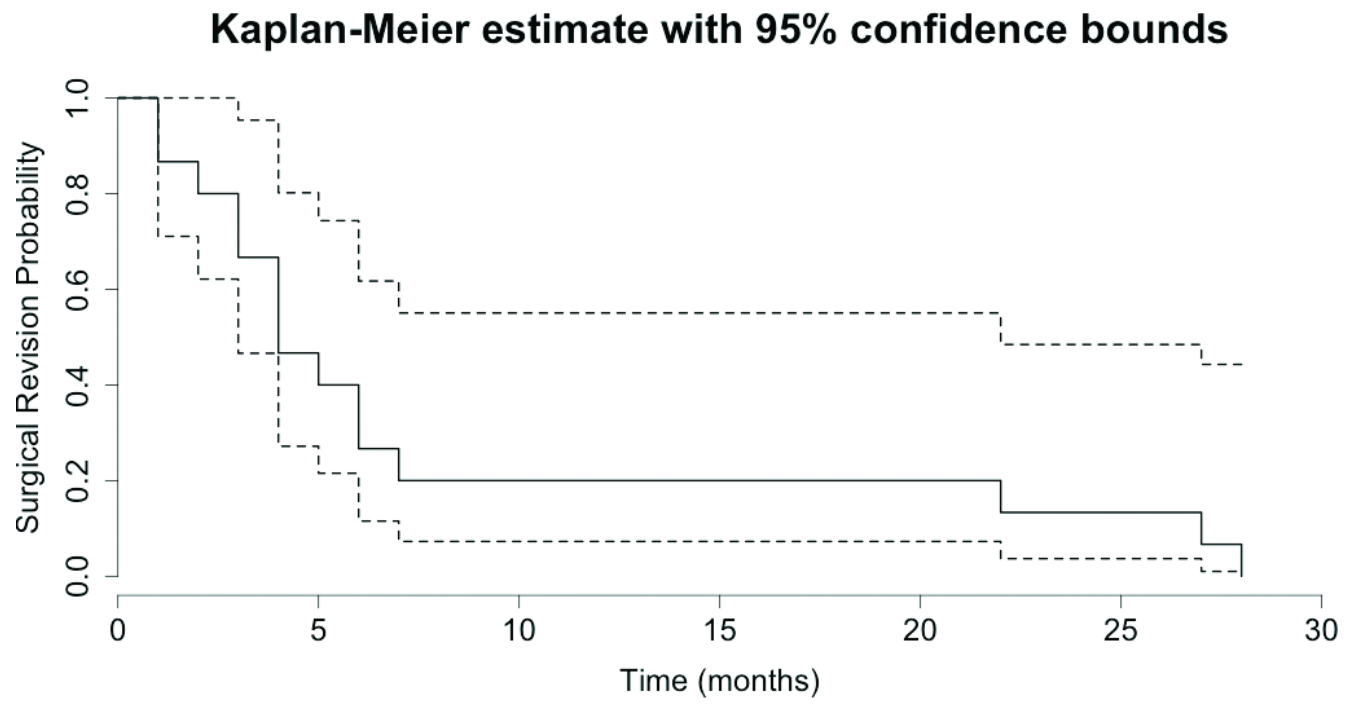

\section{FIGURE 3: Kaplan Meier curves of time to surgical revision}

The majority (71\%) of revisions occurred within a year of initial shunt surgery, and $29 \%$ of these occurred within the first three months after surgery. Among the patients requiring shunt conversion, $36 \%$ had ventriculoperitoneal shunts (five out of 14), $29 \%$ had ventriculoatrial shunts (four out of 14), 21\% had lumbopleural shunts (three out of 14), and 14\% had lumboatrial shunts (two out of 14).

Univariate logistic regression showed correlation between presence of preoperative headaches and post-LP shunt complications with an OR = 12.75 (95\% confidence interval (CI) 1.27-300.56) $\mathrm{p}=0.047$. Preoperative headaches showed correlation with complications in an univariate analysis. However, after conducting multivariate logistic regression weighted for all significant 
predictors, the relationship between preoperative headaches and post-LP shunt complications disappeared. In a further logistic regression, there was no correlation between preoperative headaches and post-LP shunt overdrainage.

As expected, when analyzing the outcomes of surgical revisions using univariate logistic regression analysis, the presence of post-LP shunt complications showed correlation with surgical revision with an OR $=16.92(95 \% \mathrm{CI} 2.91-354.52) \mathrm{p}=0.013$. As well, this relationship disappeared after conducting multivariate logistic regression weighted for all predictors. Additionally, there was no statistically significant relationship between any preoperative patient characteristic and surgical revision rate.

\section{Discussion}

Lumboperitoneal shunting minimizes intracranial risks associated with ventricular shunting systems [5, 36-41]. During the initial attempts of this technique, perioperative mortality was very high $[9,16,42]$. Substitution of polyethylene catheters by silastic catheters in 1967 led to a dramatic decline in obstruction and shunt fracture rate [42-43], although shunt complications remained a serious problem [2, 12, 23, 26, 29, 44-46]. Progress in preventing short and long-term shunt complications requiring surgical revision has been slow over the last several decades [2]. Furthermore, the literature lacks uniformity in the reporting of complication and surgical revision rates after LP shunting [2, 12-15]. This variation may be explained by the different size of previous cohorts' studies as well as the tendency to underreport poor outcomes [1, 12, 16-34].

Data shown in this manuscript is quite similar to previously reported rates in either complication or surgical reviews post-LP shunt. However, the rates we report on shunt revision are higher than other previously published ones. This may be due to the fact that in our clinical approach we include monitoring and investigating the possibility of postoperative symptoms, which could indicate possible intracranial hypotension. In our study, the presence of symptoms for overdrainage such as headaches secondary to intracranial hypotension appeared in $36 \%$ of patients with IIH post LP shunt placement. Overdrainage represented by far the largest cause of reoperation in our series. Surgical revision was performed in $89 \%$ of IHH patients with overdrainage and it could explain why there were no overdrainage related complications, such as subdural collections or acquired secondary tonsillar herniation. Thus, no decompressive posterior fossa craniectomy was required in our series. Despite this, our revision rate remains high and requires our patients to go in for multiple operations. An improvement in the valve technology will likely improve this regrettable state of affairs.

Finally, we did not find any of the following known postoperative complications after LP shunt placement in our patients: seizure, pneumoencephalus, subdural collection, venous sinus thrombosis, catheter malposition, ileus, gastrointestinal perforation, abdominal hemorrhage, myelopathy, syringomyelia, scoliosis, lumbar hyperlordosis, tonsillar herniation or acquired Chiari I malformation, preterm delivery in pregnancy, spontaneous abortion in pregnancy, or hydrocele.

The high rate of postoperative complications as well as the frequent need for multiple shunt revisions is a significant disadvantage for LP shunt. Optic nerve sheath fenestration does not fare much better because of the postoperative visual loss risk after optic nerve sheath fenestration [47-48].

We suggest the indication for shunt surgery in IIH should be reserved for those patients who experience rapid visual decline and time does not allow for alternative therapeutic strategies, those who fail other medical efforts and continue to develop visual deterioration, and those patients who are not candidates for primary therapeutic options. 
We acknowledge the limitations of our study that may influence our results: the study was not controlled or prospectively designed; it looked at data over a very long period of time; and it was characterized by loss to follow-up and incomplete medical documentation. Furthermore, the sample size may have limited the statistical power when analyzing significant associations. However, this series, limited to a single surgeon experience, reduced the variability of both indication and surgical technique derived from it as well as it tried to overcome limitations from previous studies with a more uniform cohort with adult IIH patients that have not had any previous surgery. Stronger scientific evidence requires larger samples and prospective randomized studies to compare risks and benefits of shunting in IIH versus effective weight loss and/or venous sinus stenting.

\section{Conclusions}

Our data suggests that our revisions were mostly performed to reduce the rate of post-LP shunt tonsillar herniation. The introduction of newer hardware is expected to positively impact the symptoms and signs of overdrainage post-LP shunt and the need for revision.

Surgical intervention should be carefully and prudently offered in the management of IIH. A lumbar shunt is certainly indicated when visual decline occurs rapidly and there is no to time to treat the patient with alternative medical therapeutic measures. Shunting is indicated when medical treatment, including effective weight loss and dural sinus stenting, fails.

\section{Additional Information \\ Disclosures}

Human subjects: Consent was obtained by all participants in this study. Johns Hopkins University. School of Medicine. Institutional Review Board (IRB) issued approval NA_00044584/CIR00002058. Animal subjects: All authors have confirmed that this study did not involve animal subjects or tissue. Conflicts of interest: In compliance with the ICMJE uniform disclosure form, all authors declare the following: Payment/services info: All authors have declared that no financial support was received from any organization for the submitted work. Financial relationships: All authors have declared that they have no financial relationships at present or within the previous three years with any organizations that might have an interest in the submitted work. Other relationships: All authors have declared that there are no other relationships or activities that could appear to have influenced the submitted work.

\section{Acknowledgements}

IJT was funded by the Salisbury Hydrocephalus Research Fellowship grant and the Swenson Family Foundation.

\section{References}

1. McGirt MJ, Woodworth G, Thomas G, Miller N, Williams M, Rigamonti D: Cerebrospinal fluid shunt placement for pseudotumor cerebri-associated intractable headache: Predictors of treatment response and an analysis of long-term outcomes. J Neurosurg. 2004, 101:627-32.

2. Stein SC, Guo W: Have we made progress in preventing shunt failure? A critical analysis . J Neurosurg Pediatr. 2008, 1:40-7. 10.3171/PED-08/01/040

3. Curry WT Jr, Butler WE, Barker FG 2nd: Rapidly rising incidence of cerebrospinal fluid shunting procedures for idiopathic intracranial hypertension in the United States, 1988-2002. Neurosurg. 2005, 57:97-108.

4. Yamashiro S, Hitoshi Y, Yoshida A, Kuratsu J: Historical considerations of the predominance of lumboperitoneal shunt for treatment of adult communicating hydrocephalus in Kumamoto, Japan. Clin Neurol Neurosurg. 2012, 114:1115-6. 10.1016/j.clineuro.2012.02.018 
5. Gallia GL, Rigamonti D, Williams MA: The diagnosis and treatment of idiopathic normal pressure hydrocephalus. Nat Clin Pract Neurol. 2006, 2:375-81.

6. Ball AK, Clarke CE: Idiopathic intracranial hypertension. Lancet Neurol. 2006, 5:433-42.

7. Radvany MG, Solomon D, Nijjar S, Subramanian PS, Miller NR, Rigamonti D, Blitz A, Gailloud P, Moghekar A: Visual and neurological outcomes following endovascular stenting for pseudotumor cerebri associated with transverse sinus stenosis. J Neuroophthalmol. 2013, 33:117-22. 10.1097/WNO.0b013e31827f18eb

8. Choux M, Genitori L, Lang D, Lena G: Shunt implantation: Reducing the incidence of shunt infection. J Neurosurg. 1992, 77:875-80.

9. Kestle J, Drake J, Milner R, Sainte-Rose C, Cinalli G, Boop F, Piatt J, Haines S, Schiff S, Cochrane D, Steinbok P, MacNeil N: Long-term follow-up data from the Shunt Design Trial . Pediatr Neurosurg. 2000, 33:230-236.

10. Browd SR, Ragel BT, Gottfried ON, Kestle JRW: Failure of cerebrospinal fluid shunts: Part I: Obstruction and mechanical failure. Pediatr Neurol. 2006, 34:83-92.

11. Browd SR, Gottfried ON, Ragel BT, Kestle JRW: Failure of cerebrospinal fluid shunts: Part II: Overdrainage, loculation, and abdominal complications. Pediatr Neurol. 2006, 34:171-6.

12. Sinclair AJ, Kuruvath S, Sen D, Nightingale PG, Burdon MA, Flint G: Is cerebrospinal fluid shunting in idiopathic intracranial hypertension worthwhile? A 10-year review. Cephalalgia. 2011, 31:1627-33. 10.1177/0333102411423305

13. Toma AK, Papadopoulos MC, Stapleton S, Kitchen ND, Watkins LD: Systematic review of the outcome of shunt surgery in idiopathic normal-pressure hydrocephalus. Acta Neurochir (Wien). 2013, 155:1977-8. 10.1007/s00701-013-1835-5

14. Sherman CS, Mark GB, Seema SS: Shunts in normal-pressure hydrocephalus: Do we place too many or too few?. J Neurosurg. 2006, 105:815-22.

15. Pujari S, Kharkar S, Metellus P, Shuck J, Williams MA, Rigamonti D: Normal pressure hydrocephalus: Long-term outcome after shunt surgery. J Neurol Neurosurg Psychiatry. 2008, 79:1282-6. 10.1136/jnnp.2007.123620

16. Eisenberg HM, Davidson RI, Shillito JJ: Lumboperitoneal shunts. Review of 34 cases . J Neurosurg. 1971, 35:427-31.

17. Selman WR, Spetzler RF, Wilson CB, Grollmus JW: Percutaneous lumboperitoneal shunt: Review of 130 cases. Neurosurg. 1980, 6:255-7.

18. McIvor J, Krajbich JI, Hoffman H: Orthopaedic complications of lumboperitoneal shunts. J Pediatr Orthop. 1988, 8:687-9.

19. Philippon J, Duplessis E, Dorwling-Carter D, Horn YE, Cornu P: Lumboperitoneal shunt and normal pressure hydrocephalus in elderly subjects (article in French). Rev Neurol (Paris). 1989, 145:776-80.

20. Aoki N: Lumboperitoneal shunt: Clinical applications, complications, and comparison with ventriculoperitoneal shunt. Neurosurg. 1990, 26:998-1003.

21. Brunon J, Motuo-Fotso MJ, Duthel R, Huppert J: Treatment of chronic hydrocephalus in adults by lumboperitoneal shunt. Results and indications apropos of 82 cases (article in French). Neurochirurgie. 1991, 37:173-8.

22. Easterbrook PJ, Berlin JA, Gopalan R, Matthews DR: Publication bias in clinical research . Lancet. 1991, 337:867-72.

23. Rosenberg ML, Corbett JJ, Smith C, Goodwin J, Sergott R, Savino P, Schatz N: Cerebrospinal fluid diversion procedures in pseudotumor cerebri. Neurology. 1993, 43:1071-2.

24. Chumas PD, Kulkarni AV, Drake JM, Hoffman HJ, Humphreys RP, Rutka JT: Lumboperitoneal shunting: A retrospective study in the pediatric population. Neurosurg. 1993, 32:376-83.

25. Duthel R, Nuti C, Motuo-Fotso MJ, Beauchesne P, Brunon J: Complications of lumboperitoneal shunts. A retrospective study of a series of 195 patients (214 procedures) (article in French). Neurochirurgie. 1996, 42:83-9.

26. Burgett RA, Purvin VA, Kawasaki A: Lumboperitoneal shunting for pseudotumor cerebri. Neurology. 1997, 49:734-9.

27. Chang CC, Kuwana N, Ito S: Management of patients with normal-pressure hydrocephalus by using lumboperitoneal shunt system with the Codman Hakim programmable valve. Neurosurg Focus. 1999, $7: \mathrm{e} 8$.

28. Kamiryo T, Hamada J, Fuwa I, Ushio Y: Acute subdural hematoma after lumboperitoneal shunt placement in patients with normal pressure hydrocephalus. Neurol Med Chir (Tokyo). 2003, 43:197-200. 
29. Karabatsou K, Quigley G, Buxton N, Foy P, Mallucci C: Lumboperitoneal shunts: Are the complications acceptable?. Acta Neurochir (Wien). 2004, 146:1193-7.

30. Yadav YR, Pande S, Raina VK, Singh M: Lumboperitoneal shunts: Review of 409 cases. Neurol India. 2004, 52:188-90.

31. Wang VY, Barbaro NM, Lawton MT, Pitts L, Kunwar S, Parsa AT, Gupta N, McDermott MW: Complications of lumboperitoneal shunts. Neurosurg. 2007, 60:1045-8.

32. Barcia-Marino C, Gonzalez-Bonet LG, Salvador-Gozalbo L, Goig-Revert F, Rodriguez-Mena R: Lumboperitoneal shunt in an outpatient setting for the treatment of chronic hydrocephalus in adults. A study and follow-up of 30 cases (article in Spanish). Rev Neurol. 2009, 49:300-6.

33. Jia L, Zhao ZX, You C, Liu JG, Huang SQ, He M, Ji PG, Duan J, Zeng YJ, Li GP: Minimallyinvasive treatment of communicating hydrocephalus using a percutaneous lumboperitoneal shunt. J Zhejiang Univ Sci B. 2011, 12:293-7. 10.1631/jzus.B1000248

34. Bloch O, McDermott MW: Lumboperitoneal shunts for the treatment of normal pressure hydrocephalus. J Clin Neurosci. 2012, 19:1107-11. 10.1016/j.jocn.2011.11.019

35. R Core Team: R: A language and environment for statistical computing. R Foundation for Statistical Computing, Vienna, Austria. R-Project Org,. 2013, Version 3.0.1: http://www.Rproject.org/.

36. Binder DK, Horton JC, Lawton MT, McDermott MW: Idiopathic intracranial hypertension. Neurosurg. 2004, 54:538-51.

37. Tang RA, Dorotheo EU, Schiffman JS, Bahrani HM: Medical and surgical management of idiopathic intracranial hypertension in pregnancy. Curr Neurol Neurosci Rep. 2004, 4:398-409.

38. Bergsneider M, Black PM, Klinge P, Marmarou A, Relkin N: Surgical management of idiopathic normal-pressure hydrocephalus. Neurosurg. 2005, 57:S29-39.

39. Lueck C, McIlwaine G: Interventions for idiopathic intracranial hypertension. Cochrane Database Syst Rev. 2005, Jul 20:CD003434.

40. Marmarou A, Bergsneider M, Relkin N, Klinge P, Black PM: Development of guidelines for idiopathic normal-pressure hydrocephalus: Introduction. Neurosurg. 2005, 57:S1-3.

41. Brazis PW: Clinical review: The surgical treatment of idiopathic pseudotumour cerebri (idiopathic intracranial hypertension). Cephalalgia. 2008, 28:1361-73. 10.1111/j.14682982.2008.01778.x

42. Vander Ark GD, Kempe LG, Smith DR: Pseudotumor cerebri treated with lumbar-peritoneal shunt. JAMA. 1971, 217:1832-4.

43. Jones RFC: Long-term results in various treatments of hydrocephalus . J Neurosurg. 1967, 26:313-5.

44. Pudenz RH: The surgical treatment of hydrocephalus--an historical review. Surg Neurol. 1981, 15:15-26.

45. Eggenberger ER, Miller NR, Vitale S: Lumboperitoneal shunt for the treatment of pseudotumor cerebri. Neurology. 1996, 46:1524-30.

46. Abubaker K, Ali Z, Raza K, Bolger C, Rawluk D, O'Brien D: Idiopathic intracranial hypertension: lumboperitoneal shunts versus ventriculoperitoneal shunts--case series and literature review. Br J Neurosurg. 2011, 25:94-9. 10.3109/02688697.2010.544781

47. Plotnik JL, Kosmorsky GS: Operative complications of optic nerve sheath decompression . Ophthalmology. 1993, 100:683-90.

48. Mauriello JA, Jr., Shaderowfsky P, Gizzi M, Frohman L: Management of visual loss after optic nerve sheath decompression in patients with pseudotumor cerebri. Ophthalmology. 1995, 102:441-5. 